\title{
LUMINESCENCE DATING OF AN ANCIENT WALLED SETTLEMENT IN ORKHON VALLEY, MONGOLIA
}

\author{
Tengis $S .{ }^{1 *}$, Saran $S .{ }^{1}$, Munkhbayar $L_{.}{ }^{2}$ and Bemmann $J .^{3}$ \\ ${ }^{1}$ Institute of Physics and Technology of the Mongolian Academy of Sciences, Mongolia \\ ${ }^{2}$ Institute of History and Archaeology of the Mongolian Academy of Sciences, Mongolia \\ ${ }^{3}$ Vor- und Frühgeschichtliche Archäologie, Rheinische Friedrich-Wilhelms-Universität Bonn, Germany \\ *corresponding author, e-mail: tengis@ipt.ac.mn
}

ARTICLE INFO: Received: 10 Nov, 2017; Revised: 22 Dec, 2017; Accepted: 25 Dec, 2017

\begin{abstract}
We investigated the potential of the optically stimulated luminescence (OSL) method to date young $(<1000$ years) samples collected in the Orkhon Valley Cultural Landscape, Mongolia. Quartz showed an infrared signal; therefore the post-IR OSL method was applied to small aliquots which are considered proxies for single grain measurements. Statistical analysis of the dose distribution produced CAM De of 5.14 \pm 0.10

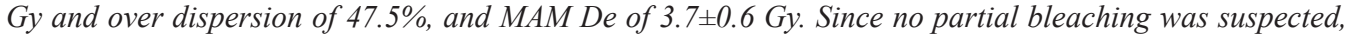
the analysis of signal composition was done and the fast quartz post-IR OSL lead to De of $4.9 \pm 0.2$ Gy. Based on the quartz fast component and CAM De we propose the new chronology of ancient construction at 785 $80 \mathrm{AD}$, rather than 906-1125 AD as suggested by archaeological evidence. However, the MAM age is in good agreement with independent age control for construction of the ramparts suggesting the date of reconstruction, collapse or reuse for the square walled enclosure MOR3 during 1090土80AD.
\end{abstract}

Keywords: Luminescence; OSL dating; quartz; fast component; Orkhon Valley;

\section{INTRODUCTION}

The luminescence technique [2] is based on the fact that many naturally occurring minerals, including quartz and feldspar are able to act as dosimeters for the amount of ionizing radiation they are exposed to. The optically stimulated luminescence (OSL) method dates the last sunlight exposure event for minerals. A basic assumption contained within the OSL approach is that the traps are completely empty of all trapped charge by sunlight during the event, which is being dated. This assumption appears to be the case with ceramics and bricks during the firing process; fired clay brick samples were successfully dated by the thermoluminescence (TL), optically stimulated luminescence (OSL) and post-infrared stimulated (pIRIR) techniques [21], [24], [20]; using different brick samples they were able to reconstruct the construction of the palatial complex, the palace and the city walls in Karakorum - the ancient capital of the Mongol Empire. However, for construction of walls and ramparts, sediment embedded within the wall may have been incorporated at various stages of the construction process, and from various sources, and may not necessarily have completely reset the OSL signal. In that case scatter in dose distributions of sedimentary samples is expected; the sources are incomplete or heterogeneous bleaching of grains [15]; [7]), post-depositional mixing of grains [18]; [13]; [23] and beta-dose 
heterogeneity in the natural burial environment [14]). Several statistical models [10] have been suggested, whose outcome is highly dependent on the uncertainties assigned to individual dose estimates.

Other sources for dispersion of the dose distribution include differences in the OSL signals response from different grains for identical treatments [4]. Internal variability leads to the observation of grains with different luminescence properties, such as brightness, and the presence of quartz grains with different OSL components [3]. For some quartz samples, isolation of the so-called 'fast component' of the OSL improves the accuracy of absorbed dose estimates [1]. A quartz fast component [4] is the signal used for $D_{e}$ evaluation using the single aliquot regenerative- $\neg$ dose protocol by [25]. The ratio of fast to medium component leads to the scatter in $D_{e}$ distributions $[24,8]$. The effect of the medium component on the dose evaluation and the ratio of fast to medium was observed for heated bricks [24].

In this study, we apply OSL dating to the walled enclosure in Orkhon Valley. Small aliquots used as a proxy for single grain measurements were analyzed using two approaches. First, we apply statistical analysis to the post-IR OSL data. Then signal

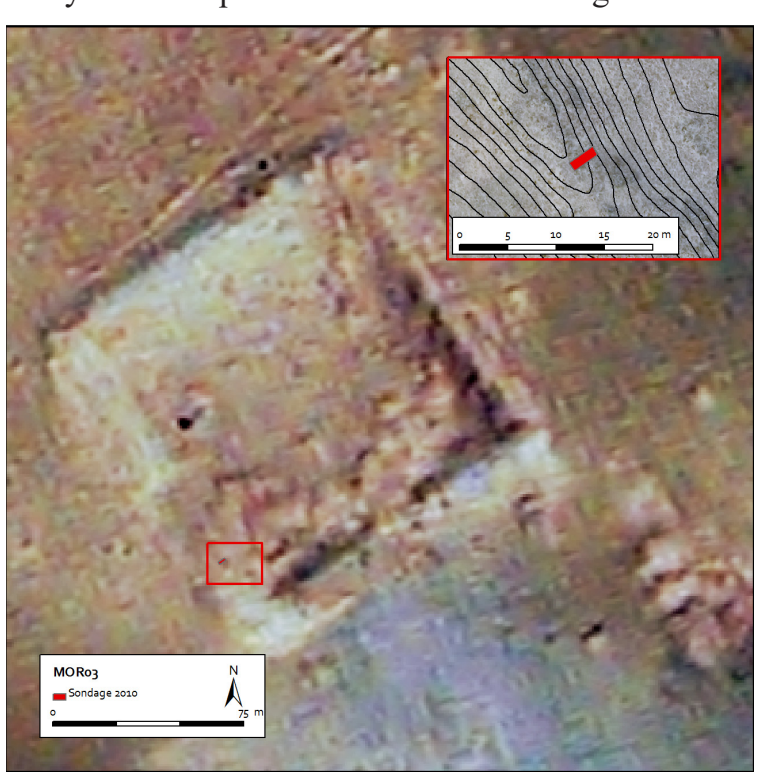

Figure 1. Walled enclosure MOR3 in Orkhon Valley (from [6]) composition analysis is used to isolate the fast signal dominated dose estimates. The results will be compared and discussed in terms of choosing the appropriate model.

\section{Sampling site}

The Orkhon Valley Cultural Landscape includes numerous archaeological remains including Karakorum, the $13^{\text {th }}$ century capital of Mongolia and Karabalgasun, the $8^{\text {th }}-9^{\text {th }}$ centuries Uighur capital. In the course of the field work of the German-Mongolian archaeological team in 2009 and 2010, the key region between the supposed spring palace of Ögödei Khan and the urban area of Karabalgasun and its archaeological structures were documented via aerial photograph analysis and ground survey [6]. Altogether 310 archaeological sites were documented in the middle and upper Orkhon Valley; these sites, the majority of which was unknown to archaeologists prior to the project, encompass more than one thousand individual features such as burials, settlements, find scatters, walled enclosure, petroglyphs etc. All periods from the Middle Paleolithic through to Post Medieval and modern times are represented [6]. 
One of this sites is a square walled enclosure (E102 $35^{\prime} 33^{\prime}$, , N $47^{\circ} 28^{\prime}$, figure 1) located to the north-west of Karabalgasun presented walled ramparts that were constructed from rammed earth; an ancient method of wall construction using local materials well represented in the Orkhon
Valley. For construction changing layers of sand, clay and gravel were moistened and then pressed into a wooden framework. The rampart itself was constructed in horizontal layers (Fig.2); construction progressing until one layer is complete and compaction of the next layer begins.

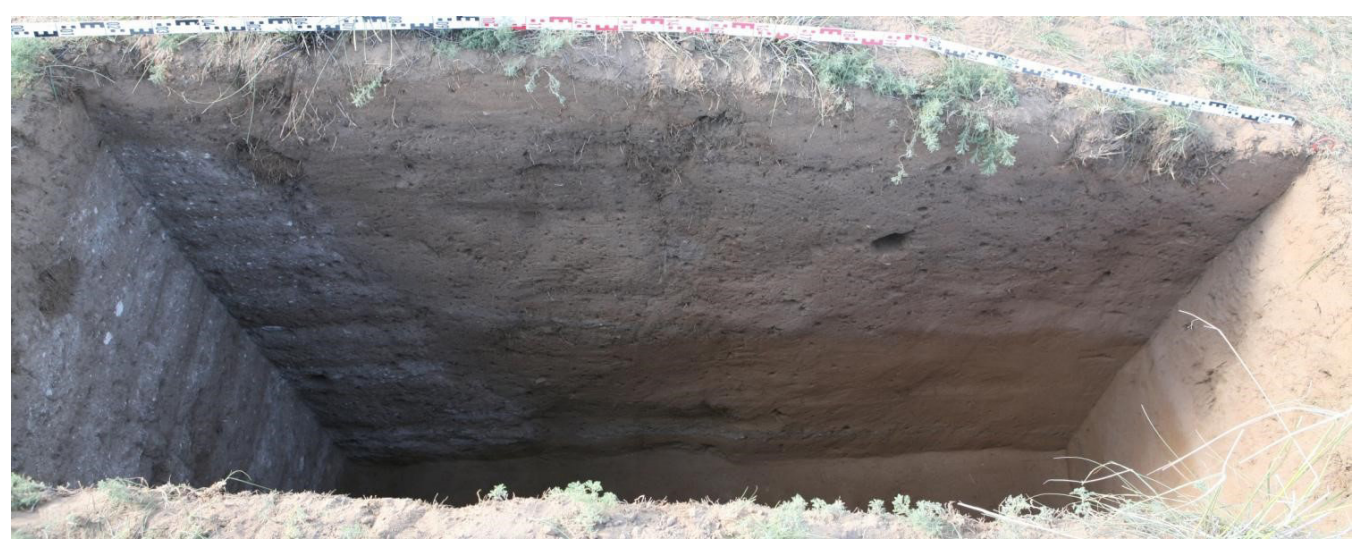

Figure 2. Test trench showing the sampling site

The test trench showed that the borders between the bands are very clear-cut which indicated that the rampart was erected from layers of rammed earth. The event to be dated is the preparation of the ramparts. Sample MOR3 was provided with independent age control

\section{EXPERIMENTAL DETAILS}

\section{Sample preparation}

Coarse grains $(>100 \mu \mathrm{m})$ were treated with $10 \% \mathrm{HCl}$ to dissolve carbonates, then dispersed using sodium oxalate and $10 \% \mathrm{H}_{2} \mathrm{O}_{2}$ to remove organic material, with a heavy liquid $\left(2.58 \mathrm{~g} \mathrm{~cm}^{-3}, 2.62 \mathrm{~g} \mathrm{~cm}^{-3}\right.$ and $\left.2.70 \mathrm{~g} \mathrm{~cm}^{-3}\right)$ to obtain quartz fractions. Quartz is finally etched with $40 \%$ HF for $40 \mathrm{~min}$ to remove the alpha irradiated outer rinds of the quartz grains, treated with $\mathrm{HCl}$ to remove insoluble fluorides and re-sieved. Coarse grains $(212 \mu \mathrm{m})$ were chosen for single grain measurements. Coarse grains $(150 \mu \mathrm{m}) 2 \mathrm{~mm}$ aliquots were prepared for OSL and post-IR OSL luminescence measurements. suggesting the construction during 906-1125 $\mathrm{AD}$ based on archaeological evidence. Clay sediment samples were collected from this ancient settlement in Orkhon Valley for the luminescence dating.

\section{Instrumentation}

Luminescence measurements were made on an automated Risø TL/OSL-DA-20 reader equipped with ${ }^{90} \mathrm{Sr} /{ }^{90} \mathrm{Y}$ beta source; with blue diodes $(\sim 470 \mathrm{~nm})$ for quartz stimulation. Quartz OSL and TL were detected through a $7.5 \mathrm{~mm}$ Hoya U-340 filter (290-370 nm) and $D_{\text {o }}$ values were determined using a SAR protocol and a double-SAR protocol.

Single grain measurements were stimulated with a green laser $\mathrm{Nd}: \mathrm{YVO}_{4}$ diode-pumped laser $(532 \mathrm{~nm})$ delivering a power density of $\sim 50 \mathrm{~W} \mathrm{~cm}^{-2}$. 


\section{OSL measurement}

The single-aliquot regenerative-dose (SAR) procedure [25] was used for equivalent dose evaluation. Additionally, a double SAR procedure [5] employed IR stimulation prior to blue stimulation. Fitting of the OSL decay curves was executed using Origin 8.6.

Dose rate measurement

The samples for dose rate determination were dried at $50^{\circ} \mathrm{C}$ until air dry and finally homogenized. $157 \mathrm{~g}$ sample material was filled into a Marinelli beaker and stored for four weeks to allow equilibrium reestablishment of ${ }^{226} \mathrm{Ra}$ and its daughter nuclides; the samples were analyzed using high-resolution gamma spectrometry. The external and internal dose rates were calculated using the conversion factors [12] and the cosmic dose rates were calculated following Prescott and Hutton [16]. In situ water content, measured shortly after sampling, was used to calculate water attenuation factors. The beta-ray attenuation factors were calculated for the grain size of $150 \mu \mathrm{m}$.

\section{RESULTS}

\section{Dose rate results}

The nuclide activities of ${ }^{238} \mathrm{U},{ }^{232} \mathrm{Th}$, ${ }^{40} \mathrm{~K}$ were converted to dose rates using the

conversion factors given in [12] and shown in Table 1.

Table 1. Radionuclide concentrations

\begin{tabular}{|c|c|c|c|c|}
\hline & ${ }^{238} \mathrm{U}, \mathrm{Bq} / \mathrm{kg}$ & ${ }^{232} \mathrm{Th}, \mathrm{Bq} / \mathrm{kg}$ & $\mathrm{Ra}-\mathrm{U}$ & ${ }^{40} \mathrm{~K}, \mathrm{~Bq} / \mathrm{kg}$ \\
\hline MOR3 & $20.11 \pm 1.00$ & $28.21 \pm 1.51$ & $20.64 \pm 1.36$ & $826.74 \pm 8.00$ \\
\hline
\end{tabular}

\section{$D_{e}$ results}

The methodology is far more advanced and better understood for quartz in comparison to feldspar and tends to give reliable estimates, however several studies dealing with OSL quartz dating reported problems with low

\section{$D_{e}$ using OSL on quartz}

Preliminary green laser stimulated single grain OSL measurements have shown that grains are dim giving around 100 counts; only 4 out of 100 grains gave doses from $1.48 \pm 0.33$ Gy to $5.15 \pm 1.05$ Gy. Therefore, small aliquots A small aliquot is an average of up to 100 grains; were used as proxy for single grains

$$
I(t)=\sum_{i=1}^{N} n_{i} p_{i} \exp \left(-p_{i} t\right)+c
$$

where $n_{i}$ - concentration of electrons at the $i$-th trap; $p_{i}$ - detrapping probability of electrons from the $i$-th trap; $c$ - constant. The detrapping probability is the product of the photoionization cross-section and the luminescence efficiency observed most commonly in young samples [17]. To obtain an accurate $D_{e}$ we investigate the samples using two approaches: statistical analysis and signal composition analysis.

measurements.

Blue stimulated OSL curves are shown in Fig.3. To examine whether the obtained OSL signal originates from more than one electron trap [25], the OSL decay curves were fitted with a sum of exponential components using the equation [22]:

stimulation intensity.

The fitting results indicate that the fast OSL component and the medium OSL dominate for the initial time period and the slow component is contributing to the overall 
signal. Furthermore, the quartz sample with a dominant medium component showed an infrared contaminated signal. The IRSL and blue stimulated post-IR OSL signals are very similar in intensity.

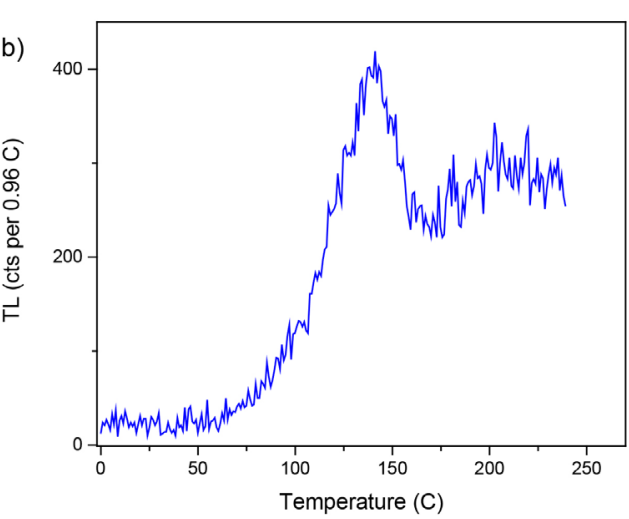

Figure 3. a) OSL signal showing different components; b) TL peaks at $110^{\circ} \mathrm{C}$ and $200^{\circ} \mathrm{C}$; the latter is an indication of presence of feldspar

Table 2. Fitting parameters obtained for two different OSL signals

\begin{tabular}{|c|c|c|c|}
\hline & & fast & medium \\
\hline \multirow{2}{*}{ fast } & $\mathrm{n} 1$ & $220 \pm 5$ & - \\
\cline { 2 - 4 } & $\mathrm{p} 1, \mathrm{~s}-1$ & $2.57 \pm 0.06$ & - \\
\hline \multirow{2}{*}{ medium } & $\mathrm{n} 2$ & - & $923 \pm 20$ \\
\cline { 2 - 4 } & $\mathrm{p} 2, \mathrm{~s}-1$ & - & $0.80 \pm 0.02$ \\
\hline \multirow{2}{*}{ slow } & $\mathrm{n} 3$ & $3179 \pm 216$ & $3392 \pm 153$ \\
\cline { 2 - 4 } & $\mathrm{p} 3, \mathrm{~s}-1$ & $0.02 \pm 0.001$ & $0.03 \pm 0.002$ \\
\hline
\end{tabular}

To further investigate the behavior of quartz, the corresponding TL glow curves where the $D_{e}$ were already evaluated were recorded using small aliquots. Fig. $3 \mathrm{~b}$ shows the TL curves obtained when heating to $450^{\circ} \mathrm{C}$, immediately after beta irradiation (4 Gy) and following $10 \mathrm{~s}$ preheat at $70^{\circ} \mathrm{C}$. The $\mathrm{TL}$ glow curves show that there are two dominant TL peaks, one at $110^{\circ} \mathrm{C}$ and an additional intermediate peak around $200^{\circ} \mathrm{C}$ was obtained for sample MOR3. It can be speculated that there is a correlation between the presence of an infrared signal and the presence of a significant medium component.

\section{$D_{e}$ using post-IR OSL on quartz}

For MOR3, 24 single aliquots were measured using post-IR OSL which is a technique that stimulates the same aliquot with infra-red (IR) light followed by blue light stimulation [5].

Effect of the precision criteria

The single-aliquot $D_{e}$ distributions are shown using Abanico plots in Figure 4. The sample showed a broad dose distribution: the $D_{e}$ varies from $\sim 1$ Gy to $\sim 16$ Gy. Grain-tograin variations are assumed to contribute to the $D_{e}$ scatter. 


\section{ML-5 30\%}
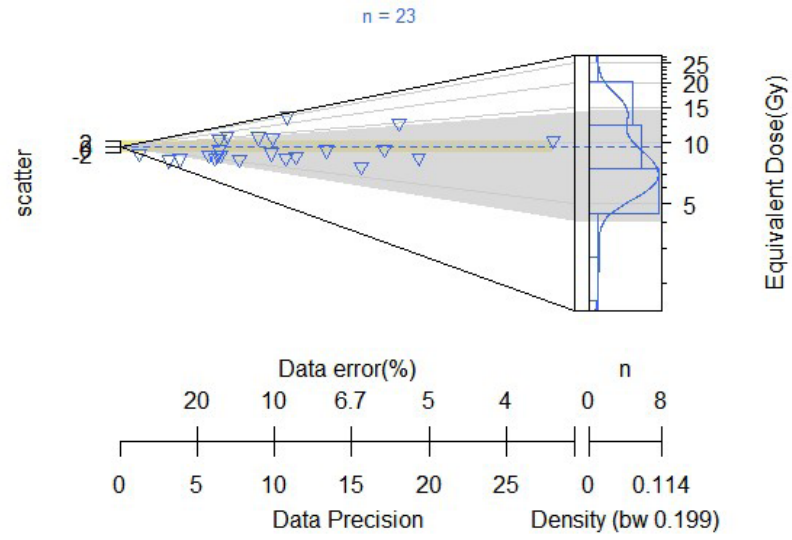

\section{ML-5 20\%}

$$
n=20
$$

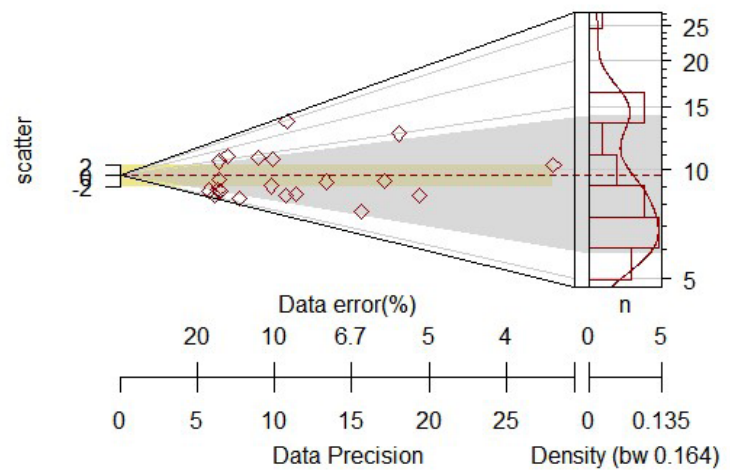

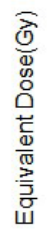

\section{ML-5 10\%}

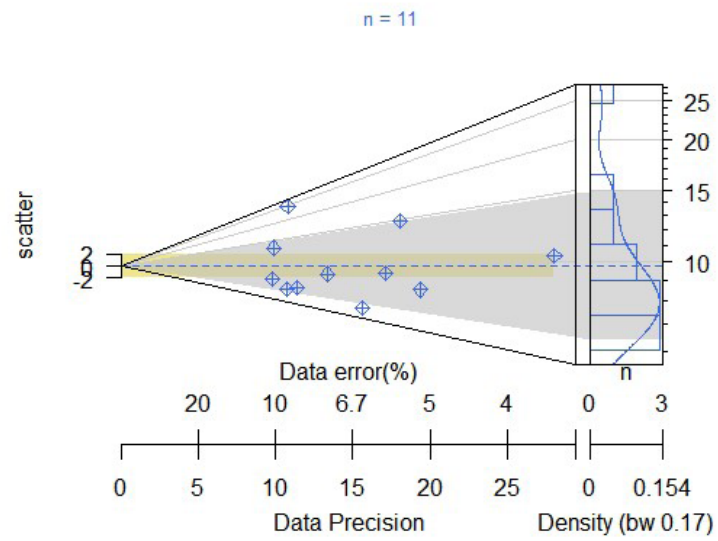

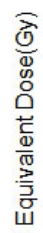

Figure 4. Dose distributions displayed using the Abanico plots for the precision on $D_{e}<30,<20,<10 \%$ 
Overdispersion (OD) in a $D_{e}$ distribution is a quantitative measure that refers to the relative standard deviation of the distribution of true single grain $D_{e}$ values from a central $D_{e}$ value, after having allowed for estimation of the statistical error [11]. The choice of model, e.g. central age (CAM), minimum age (MAM) or finite mixture model (FMM) [11], is based on the OD value. This choice assumes that the precision assigned to each $D_{e}$ measurement is correctly calculated. Many studies have reported up to $20 \%$ overdispersion among $D_{e}$ estimates for single aliquots that have been well bleached [13] [9].

Individual aliquots with precision on $D_{e}<30 \%$ were analyzed using statistical tools [11], CAM $D_{e}$ is $5.14 \pm 0.54$ Gy and overdispersion of $47.5 \%$. MAM $D_{e}$ was $3.7 \pm 0.6$ Gy .. The effect of the acceptance

$$
\frac{L_{x}}{T_{x}}=a\left(1-\exp \left(-\frac{D}{B}\right)\right)
$$

Aliquots with dominant fast component and dominant medium component yield $D_{e}$ of $4.9 \pm 0.2$ Gy and $7.39 \pm 0.87$ Gy, respectively. In concordance with previous speculations, medium OSL component gave higher doses

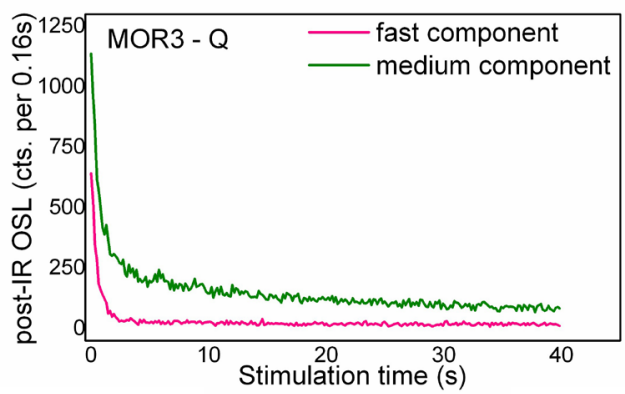

criteria on dose estimate was analyzed for the precision on $D_{e}<20 \%$ and $<10 \%$, respectively. With the increase on the precision the number of aliquots decreased from $n=23$ to $n=11$ $(<10 \%)$. These precise dose estimates gave CAM $D_{e}$ of $4.21 \pm 0.22$ Gy and over dispersion of $17.7 \%$. The CAM and MAM $D_{e}$ values, the precision on $D_{e}$, the number of aliquots, over dispersion values are shown in Figure 4 and summarized in Table 3.

\section{Effects of signal composition on $D_{e}$}

The post-IR OSL signals are shown in Fig.5. We observed that the luminescence efficiency varied between aliquots; and the aliquots showing high luminescence efficiency showed a contribution from other components than the fast component. The corresponding growth curves were fitted using

than the fast OSL component. Fitting results on 23 single aliquots of sample MOR3 revealed that only 4 aliquots comprised the dominant fast OSL component.

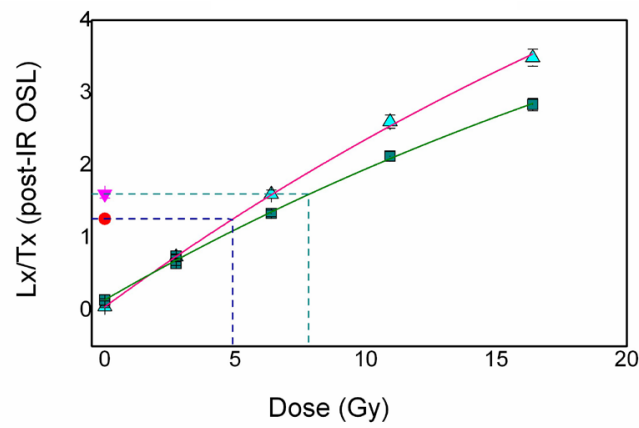

Figure 5. post-IR OSL signal, fast component (red) and medium component (green) 


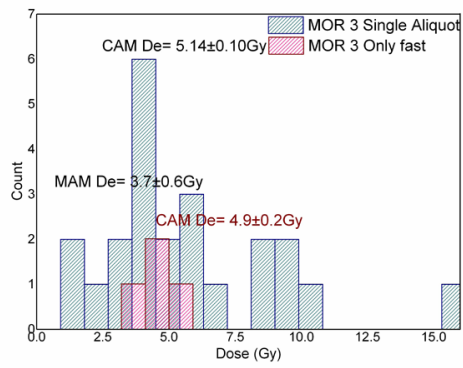

Figure 6. Dose distributions for quartz sample MOR3: all De estimates are shown blue and De derived only from fast components is shown red

Figure 6 shows dose distributions as histograms for all dose estimates (blue) and for

\section{DISCUSSION AND CONCLUSION}

For the site MOR-3 single grain analysis failed due to dim signals, it was not possible to carry out reliable single grain measurements for the young sample under study. The smallaliquots comprise of 100 grains from which up to 3-4 grains might contribute to the dose estimate. Furthermore, the small-aliquots showed an infrared signal relating either to the presence of feldspar (REF) or to the medium OSL component. TL peak around $200^{\circ} \mathrm{C}$ which is indicative for feldspar was apparent for grains showing a dominant medium
$D$ derived from fast component comprising $4.9 \pm 0.2$ Gy. component.

$D_{e}$ distributions of post-IRSL OSL measurements on quartz were highly overdispersed: the CAM $D_{e}$ is $5.14 \pm 0.10$ Gy with OD of $47.5 \%$. To improve the accuracy of the $D_{e}$ estimation, the acceptance criteria based on the precision on $D_{e}$ were applied and the most precise 11 aliquots yield the CAM $D_{e}$ of $4.21 \pm 0.22$ Gy and OD of $13.3 \%$. Because of this apparent discrepancy further statistical analysis were made.

Table 3. Summary of dose, dose rate and age results for samples.

The selected De and ages are indicated bold

\begin{tabular}{|l|c|c|c|c|}
\hline \multicolumn{1}{|c|}{ MOR-3 } & $\sigma \mathrm{De}<30 \%$ & $\sigma \mathrm{De}<20 \%$ & $\sigma \mathrm{De}<10 \%$ & De from fast OSL \\
\hline $\mathrm{N}$ aliquots & 23 & 20 & 11 & 4 \\
\hline CAM $D_{e}$, Gy & $\mathbf{5 . 1 4} \pm \mathbf{0 . 1}$ & $4.37 \pm 0.3$ & $4.21 \pm 0.22$ & $\mathbf{4 . 9} \pm \mathbf{0 . 2}$ \\
\hline OD, $\%$ & 47.5 & 40.2 & 17.7 & 10.3 \\
\hline MAM $D_{e}$, Gy & $3.7 \pm 0.6$ & - & - & - \\
\hline Dr, Gy/ka & \multicolumn{5}{|c|}{$3.99 \pm 0.17$} \\
\hline MAM age, (years) & $\mathbf{9 3 0} \pm \mathbf{8 0}$ (1090 AD) & - & - & - \\
\hline CAM age, (years) & $\begin{array}{r}\mathbf{1 2 9 0} \pm \mathbf{7 0} \\
\mathbf{( 7 2 5} \pm \mathbf{7 0} \text { AD) }\end{array}$ & $\begin{array}{c}1100 \pm 100 \\
(920 \pm 100 \mathrm{AD})\end{array}$ & $\begin{array}{c}1055 \pm 80 \\
(960 \pm 80 \mathrm{AD})\end{array}$ & $\begin{array}{c}\mathbf{1 2 3 0} \pm \mathbf{8 0} \\
\mathbf{( 7 8 5} \pm \mathbf{8 0} \text { AD) }\end{array}$ \\
\hline
\end{tabular}


Statistical models are powerful at revealing the incomplete bleaching and post-depositional mixing or disturbance [11] which might result in distinct dose populations. Post-depositional disturbance may be discounted if sedimentary structures or layering are preserved. But such features are not always evident, especially at archaeological sites because of anthropogenic activities [19]. Assuming an incomplete bleaching at the deposition and applying the minimum dose model, we obtained the MAM dose of $3.7 \pm 0.6 \mathrm{~Gy}$.

In contrast, signal composition of the post-IR OSL through fitting revealed that the initial signal was dominated by fast or medium components. Signals dominated by the medium component yield higher luminescence efficiency and give higher dose estimates than the fast components. Based on the accepted $\mathrm{n}=4$ aliquots showing the fast component dominated signal, we obtain $D_{e}$ of $4.9 \pm 0.2 \mathrm{~Gy}$.

This apparent discrepancy between the $D_{e}$ obtained from the fast component and $D_{e}$ obtained from the most precise dose estimates means that the most precise estimates were derived from the aliquots showing other components than the fast OSL, which are much brighter and consequently have error on the $D_{e}$ estimate $<10 \%$. The dose $D_{e}$ obtained from the fast OSL is consistent with CAM $D_{e}$

\section{Acknowledgements}

The luminescence measurements were conducted at luminescence laboratory Köln. Tengis's work was financed by the research grant from the Mongolian Science and derived with precision on $D_{e}<30 \%$.

Summary of the luminescence results are shown in Table 3.

We conclude that

1. Small-aliquots as proxy single-grain measurements gave an opportunity to compare the doses evaluated using two different approaches, namely the statistical modeling and signal composition analysis.

2. The signal composition analysis is reliable due to the well-known signal parameters of blue stimulated fast and medium components. It revealed that the brighter grains with different luminescence characteristics may yield higher doses which were erroneously accepted due to high precision by using the statistical modeling. Further analysis of single grains and analysis of fast and medium components is needed to verify the findings and to improve the accuracy of dose estimation.

3. The walled enclosure MOR 3 was constructed not as expected during the 906-1125 AD based on the archaeological evidence, but during $785 \pm 80 \mathrm{AD}$. In addition, the possibility of rebuilding, reusing or collapse of the ramparts during the $1090 \pm 80$ $\mathrm{AD}$ cannot be ruled out due to the MAM age of $930 \pm 80$ years.

Technology Foundation. Research stay of Saran Solongo was financed by DAAD. The anonymous reviewer is thanked for providing constructive comments. 


\section{REFERENCES}

1. Adamiec, G., A. Bluszcz, R. Bailey, and M. Garcia-Talavera, Finding model parameters: Genetic algorithms and the numerical modelling of quartz luminescence. Radiation Measurements, 2006. 41(7-8): p. 897-902.

2. Aitken, M.J., An introduction to optical dating. The dating of Quaternary sediments by the Use of Photon-Stimulated Luminescence 1998: Oxford, New York, Tokyo: Oxford University Press.

3. Bailey, R.M., B.W. Smith, and E.J. Rhodes, Partial bleaching and the decay form characteristics of quartz OSL. Radiation Measurements, 1997. 27(2): p. 123-136.

4. Bailey, R.M., E.G. Yukihara, and S.W.S. McKeever, Separation of quartz optically stimulated luminescence components using green $(525 \mathrm{~nm})$ stimulation. Radiation Measurements, 2011. 46(8): p. 643-648.

5. Banerjee, D., A.S. Murray, L. Bøtter-Jensen, and A. Lang, Equivalent dose estimation using a single aliquot of polymineral fine grains. Radiation Measurements, 2001. 33(1): p. 73-94.

6. Bemmann, J., B. Ahrens, C. Grützner, R. Klinger, N. Klitzsch, F. Lehmann, S.Linzen, L. Munkhbayar, G. Nomguunsuren, M. Oczipka, H. Piezonka, B. Schütt, and S.Saran, Geoarchaeology in the steppe: first results of the multidisciplinary Mongolian-German survey project in the Orkhon valley, central Mongolia. Studia Archaeologica Instituti Archaelogici Academiae Scientiarium Mongolicae, XXX, Fasciulus, 2011.

7. Bøtter-Jensen, L., S. Solongo, A.S. Murray, D. Banerjee, and H. Jungner, Using the OSL single-aliquot regenerative-dose protocol with quartz extracted from building materials in retrospective dosimetry. Radiation Measurements, 2000. 32(5-6): p. 841-845.

8. Duller, G.A.T., Improving the accuracy and precision of equivalent doses determined using the optically stimulated luminescence signal from single grains of quartz. Radiation Measurements, 2012. 47(9): p. 770-777.

9. Fattahi, M., M. Heidary, and M. Ghasemi, Employing Minimum age model (MAM) and Finite mixture modeling (FMM) for OSL age determination of two important samples from Ira Trench of North Tehran Fault, in Geochronometria. 2016. p. 38.

10. Galbraith, R.F. and R.G. Roberts, Statistical aspects of equivalent dose and error calculation and display in OSL dating: An overview and some recommendations. Quaternary Geochronology, 2012. 11: p. 1-27.

11. Galbraith, R.F., R.G. Roberts, G.M. Laslett, H. Yoshida, and J.M. Olley, Optical Dating of Single and multiple grains of quartz from jinmium rock shelter, northern Australia: part 1, Experimental Design and statistical models. Archaeometry, 1999. 41(2): p. 339364.

12. Guerin, G., N. Mercier, and G. Adamiec, Dose-rate conversion factors: update. 2011, Ancient TL. p. 5-8.

13. Jacobs, Z., G.A.T. Duller, and A.G. Wintle, Interpretation of single grain distributions and calculation of. Radiation Measurements, 2006. 41(3): p. 264-277.

14. Nathan, R.P., P.J. Thomas, M. Jain, A.S. Murray, and E.J. Rhodes, Environmental dose rate heterogeneity of beta radiation and its implications for luminescence dating: Monte Carlo modelling and experimental validation. Radiation Measurements, 2003. 37(4): $p$. 305-313.

15. Olley, J., G. Caitcheon, and A. Murray, The distribution of apparent dose as determined by Optically Stimulated Luminescence in small aliquots of fluvial quartz: Implications for dating young sediments. Quaternary Science Reviews, 1998. 17(11): p. 1033-1040.

16. Prescott, J.R. and J.T. Hutton, Cosmic ray contributions to dose rates for luminescence and ESR dating: Large depths and long-term time variations. Radiation Measurements, 1994. 23(2-3): p. 497-500. 
17. Preusser, F., M.L. Chithambo, T. Götte, M. Martini, K. Ramseyer, E.J. Sendezera, G.J. Susino, and A.G. Wintle, Quartz as a natural luminescence dosimeter. Earth-Science Reviews, 2009. 97(1-4): p. 184-214.

18. Roberts, R.G., Luminescence dating in archaeology:from origins to optical. Radiation Measurements, 1997. 27(5): p. 819-892.

19. Roberts, R.G., Z. Jacobs, B. Li, N.R. Jankowski, A.C. Cunningham, and A.B. Rosenfeld, Optical dating in archaeology: thirty years in retrospect and grand challenges for the future. Journal of Archaeological Science, 2015. 56: p. 41-60.

20. Saran, S., S. Tengis, and B. Tsogtbaatar, WHAT THE BRICKS TELL US FROM A TEMPLE AT BURKHAN KHALDUN MOUNTAINS: CHRONOLOGICAL INSIGHTS FROM pIRIR LUMINESCENCE. Proceedings of the Mongolian Academy of Sciences, 2016. 4: p. 4-12.

21. Saran, S., G.A. Wagner, and T. Galbaatar, The chronology of brick manufacturing at the Kharakhorum, Mongolia. . Preprints of the Institute of Physics and Technology, MAS, 2006. 33: p. 60-64.

22. Solongo, S., D. Richter, B. Tuguldur, and J.J. Hublin, OSL and TL characteristics of fine grain quartz from Mongolian prehistoric pottery used for dating. Geochronometria, 2014. 41(1): p. 15-23.

23. Solongo, S., S. Tengis, N. Erdene-Ochir, and J.-J. Hublin, Testing the pIRIR on pottery and SG-OSL on clay sediment from the known age Xiongnu "Royal" tomb at Noin Ula, Mongolia. Archaeological and Anthropological Sciences, 2017.

24. Solongo, S., G.A. Wagner, and T. Galbaatar, The estimation of using the fast and medium components in fired quartz from archaeological site Karakorum, Mongolia. Radiation Measurements, 2006. 41(7-8): p. 1001-1008.

25. Wintle, A.G. and A.S. Murray, A review of quartz optically stimulated luminescence characteristics and their relevance in single-aliquot regeneration dating protocols. Radiation Measurements, 2006. 41(4): p. 369-391. 